\title{
3 Modelagem Matemática como metodologia para o ensino de Matemática nos anos iniciais
}

alguns apontamentos sobre a abordagem dos conteúdos matemáticos a partir de relatos de experiências

Vantielen da Silva Silva

\section{SciELO Books / SciELO Livros / SciELO Libros}

SILVA, V. S. Modelagem Matemática como metodologia para o ensino de Matemática nos anos iniciais: alguns apontamentos sobre a abordagem dos conteúdos matemáticos a partir de relatos de experiências. In: BRANDT, C. F., BURAK, D., and KLÜBER, T. E., orgs. Modelagem matemática: perspectivas, experiências, reflexões e teorizações [online]. 2nd ed. rev. and enl. Ponta Grossa:

Editora UEPG, 2016, pp. 59-74. ISBN 978-85-7798-232-5. Available from: doi:

10.7476/9788577982325.0004. Also available in ePUB from:

http://books.scielo.org/id/b4zpq/epub/brandt-9788577982325.epub.

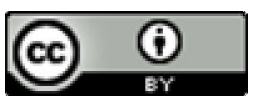

All the contents of this work, except where otherwise noted, is licensed under a Creative Commons Attribution $\underline{4.0 \text { International license. }}$

Todo o conteúdo deste trabalho, exceto quando houver ressalva, é publicado sob a licença Creative Commons Atribição 4.0.

Todo el contenido de esta obra, excepto donde se indique lo contrario, está bajo licencia de la licencia Creative Commons Reconocimento 4.0 . 


\section{Modelagem Matemática como metodologia para o ensino de Matemática nos anos iniciais: alguns apontamentos sobre a abordagem dos conteúdos matemáticos a partir de relatos de experiências}

Vantielen da Silva Silva

\section{Introdução}

O ensino de Matemática nos anos iniciais, assim como em outras etapas da Educação Básica, objetiva instigar a construção e a apropriação de conhecimentos necessários à formação do cidadão crítico e reflexivo, um sujeito capaz de compreender e identificar a matemática no seu cotidiano e, ao mesmo tempo, utilizar estes conhecimentos para inovar, transformar (BRASIL, 1997). Dito de outra forma, é papel da escola oferecer subsídios para que o aluno compreenda seu ambiente natural, social, político, aprenda sobre ciência e tecnologia, construa valores e outros aspectos indispensáveis para a atuação e convivência em nossa sociedade.

Tendo em vista estas finalidades, a educação escolar necessita assumir uma perspectiva problematizadora, de caráter reflexivo, um meio de desvelar a realidade (FREIRE, 2005) e, no caso específico da Matemática, almeja-se uma educação que "não seja preparação para a vida, e sim vida, [...] que não seja preparação para a ação, e sim ação" (LINS, 1999, p. 94).

Diante disso, luta-se por um ensino de Matemática que objetive, muito além das melhorias dos índices das avaliações nacionais, a aprendizagem significativa dos alunos, de todas as etapas da Educação Básica, ou seja, que os conteúdos e conceitos presentes na Matemática se relacionem com o seu cotidiano, com sua vida, com suas compreensões sobre o mundo.

A Modelagem Matemática, considerando o exposto, tem sido referenciada como uma metodologia com esse potencial para o trabalho com a matemática nos anos iniciais. É uma metodologia que instiga a participação ativa, a interação, contextualização, problematização; interdisciplinaridade e diálogo investigativo (SILVA; KLÜBER, 2011; 2014), aspectos necessários para um aprender significativo e para ruptura de um ensino mecânico.

Apesar dos fatores mencionados tornarem a Modelagem um caminho destacável para o processo de ensino e aprendizagem de Matemática nos anos iniciais, essa proposta causa estranhamento e mal estar ao corpo docente 
que se preocupa incessantemente em cumprir os programas das disciplinas, o currículo escolar (BURAK, 1987; 1992).

Pensando nesta condição, buscamos desenvolver um trabalho que nos ajudasse a responder a seguinte questão: $O$ que se revela sobre a abordagem dos conteúdos especificos de Matemática na Modelagem Matemática nos anos iniciais do Ensino Fundamental apresentadas em trabalhos de conclusão de curso?

Essa problemática foi direcionada às pesquisas sobre Modelagem Matemática nos anos iniciais, desenvolvidas e presentes no acervo da biblioteca da Universidade Estadual do Centro-Oeste, Unicentro. Estas pesquisas, para melhor esclarecer, se configuram em relatos de experiência. Nessa instituição, segundo Burak (2005), são desenvolvidos trabalhos sobre Modelagem Matemática desde a década de 1980, sendo uma das primeiras a demonstrar, por meio dos trabalhos dos professores pesquisadores, preocupação com o ensino de Matemática e criar iniciativas para mudanças no contexto.

Além disso, tal proposta corrobora com as investigações e discussões empreendidas no grupo de pesquisa, vinculado à referida instituição, sobre Modelagem Matemática na Educação Matemática. Também, os trabalhos mapeados revelam certo pioneirismo do referido grupo no que concerne Modelagem Matemática e, mais especificamente, ao seu uso nos anos iniciais, cujas pesquisas, ainda, são incipientes.

Um aspecto a ser acrescentado refere-se ao fato de que os trabalhos apresentados na sequência, embora sejam predominantemente desenvolvidos e orientados na perspectiva de Burak, não se pode desconsiderar que há outras produções e pesquisas sendo empreendidas, recentemente, nessa etapa da Educação Básica.

No acervo bibliotecário foram mapeadas 46 investigações sobre Modelagem Matemática na concepção da Educação Matemática, sendo mais presentes experiências desenvolvidas em turmas referentes aos anos finais do Ensino Fundamental e Ensino Médio. Destas, apenas quatro (04) produções relatam experiências com crianças nos anos iniciais, conforme apresentado no Quadro 1: 
Quadro 1 - Trabalhos de conclusão de curso

\begin{tabular}{|c|c|c|c|}
\hline Título dos trabalhos & Autoria & $\begin{array}{l}\text { Ano de } \\
\text { divulgação }\end{array}$ & $\begin{array}{l}\text { Cursos } \\
\text { vinculados }\end{array}$ \\
\hline $\begin{array}{l}\text { Modelagem Matemática: uma } \\
\text { metodologia para o ensino de } \\
\text { Matemática na } 3^{\mathrm{a}} \text { série do } 1^{\circ} \text { grau }\end{array}$ & $\begin{array}{l}\text { Ione Maria } \\
\text { Gasperin }\end{array}$ & 1990 & \multirow{3}{*}{$\begin{array}{l}\text { Especialização } \\
\text { em Ensino de } \\
\text { Matemática e } \\
\text { Ciências }\end{array}$} \\
\hline $\begin{array}{l}\text { Modelagem Matemática: uma } \\
\text { metodologia para o ensino de } \\
\text { Matemática na } 4^{\mathrm{a}} \text { série do } 1^{\circ} \\
\text { grau. }\end{array}$ & $\begin{array}{l}\text { Maria Elena } \\
\text { Prado dos } \\
\text { Santos }\end{array}$ & 1990 & \\
\hline $\begin{array}{l}\text { Alfabetização Matemática: uma } \\
\text { experiência com Modelagem } \\
\text { Matemática. } 1993\end{array}$ & $\begin{array}{l}\text { Marta Ione } \\
\text { Tozzeto }\end{array}$ & 1993 & \\
\hline $\begin{array}{l}\text { Modelagem Matemática: } \\
\text { construindo a } \\
\text { interdisciplinaridade }\end{array}$ & $\begin{array}{l}\text { Vera Lúcia } \\
\text { Lapczak } \\
\text { Brautigam }\end{array}$ & 2001 & $\begin{array}{l}\text { Especialização } \\
\text { em } \\
\text { Psicopedagogia }\end{array}$ \\
\hline
\end{tabular}

Fonte: Pesquisa Própria.

A pesquisa de Tozetto (1993) refere-se a uma investigação com crianças da primeira série, hoje $2^{\circ}$ ano do $1^{\circ}$ ciclo dos anos iniciais. Ciclo caracterizado como um momento de aproximação aos conceitos e conteúdos matemáticos, no que tange a construção dos números, escrita numérica, operações, entre outros (BRASIL, 1997).

Por sua vez, a pesquisa de Gasperin (1990), refere-se à $3^{\text {a }}$ série, atual $4^{\mathrm{o}}$ ano dos anos iniciais do Ensino Fundamental e as pesquisas de Santos (1990) e Brautigam (2001) evidenciam experiências com a $4^{a}$ série, hoje $5^{\circ}$ ano dos anos iniciais do Ensino Fundamental. Neste segundo ciclo, "os alunos ampliam conceitos já trabalhados no ciclo anterior (como o de número natural, adição, medida, etc.)" (BRASIL, 1997, p. 57). Também se aproximam de novos conceitos e aperfeiçoam os já construídos.

Os quatro relatos citados expressam que a Modelagem Matemática foi utilizada na tentativa de promover aulas lúdicas e interativas, contando com a participação das crianças. Num contexto em que as aulas eram essencialmente transmissivas, o uso da Modelagem representou uma mudança de perfil no planejamento dos professores. Num primeiro momento, a partir da leitura global, identificamos as principais características apresentadas pelos pesquisadores a respeito da Matemática e, num segundo momento, 
enfocamos na compreensão de como os conteúdos específicos são tratados a partir do uso desta metodologia.

\section{A Modelagem Matemática no contexto dos anos iniciais: importância e contribuições}

Gasperin (1990), Santos (1990), Tozetto (1993) e Brautigam (2001), autoras das pesquisas em discussão, expressam discursos convergentes à necessidade de provocar melhorias no ensino de Matemática por meio do uso da Modelagem Matemática. Para as autoras, um ensino de Matemática transmissivo, que supervaloriza o abstrato numa etapa em que a construção ocorre e necessita de materiais concretos, ignora a possibilidade de que as crianças aprendam ativamente, dialogando, interagindo, investigando, explorando o meio e o vivido. Como se Matemática fosse algo a ser simplesmente assimilado e introjetada de modo direto.

As referidas autoras, explicitando estas considerações, desenvolveram seus trabalhos com a Modelagem Matemática, objetivando "propor uma metodologia alternativa para o ensino" (SANTOS, 1990, p. 10); "dinamizar as aulas de matemática" (GASPERIN, 1990, p. 07); "resgatar o gosto e o interesse do aluno pela Matemática" (TOZETTO, 1993, p. 06) e "tornar as aulas da disciplina um processo dinâmico, participativo" (BRAUTIGAM, 2000, p. 08). Essas são indicações de que as aulas de Matemática, considerando Carraher (et al. 1988), não podem se limitar ao espaço sala de aula ou à reprodução e cumprimento de livros didáticos e necessita relacionar matemática formal e cotidiana, uma vez que a ausência de contextualização pode ser uma das principais causas da desmotivação pelo aprender Matemática.

Os objetivos descritos sobre o uso da Modelagem salientam a compreensão de que o ensino não é meramente instrução e que a metodologia, considerada como forma de proceder ou organizar o ensino, é de fundamental importância para a promoção de um ensino significativo. Partindo dessa compreensão, alguns fatores descritos podem ser destacados:

A Modelagem Matemática propõe uma forma de aprendizagem dinâmica para o aluno. Procurando através da ação, do fazer chegar ao saber e contribuir para amenizar a crise que assola a educação, mais especificamente o ensino de matemática (GASPERIN, 1990. p. 10).

O ensino através da Modelagem propicia ao aluno trazer à tona situações problemas do seu dia-a-dia, tornando o aprendizado mais fácil, pois o mesmo identifica-se como personagem e não como mero reprodutor (SANTOS, 1990, p. 07). 
Através da Modelagem Matemática, busca-se dar uma nova imagem à Matemática, ou seja, superar a ansiedade que se criou em torno da disciplina, pois todos são capazes de aprendê-la, valorizar todos os conhecimentos trazidos para escola pelo aluno, recriando o que está criado, demonstrando e evidenciando a mudança de atitude de aluno, pois passa a realizar uma leitura crítica da matemática, inserindo-a no contexto sociopolítico e econômico vividos por ele em todos os momentos (TOZETTO, 1993, p. 53).

A Modelagem Matemática representa a possibilidade de tornar as aulas da disciplina num processo dinâmico, participativo e com resultados que os alunos podem comprovar na sua realidade diária, criando vínculos mais fortes entre o aluno e os conteúdos expostos (BRAUTIGAM, 2001, p. 07).

Tal como explicitado pelos pesquisadores, a Modelagem Matemática, pelo menos em parte, é concebida como uma possível solução para os problemas vividos no ensino de Matemática, problemas estes concernentes à desmotivação pelo ato de aprender, reprovações, baixo rendimento, entre outros aspectos considerados produtos de um ensino sem contextualização (LOPES et al., 2011).

A importância da Modelagem Matemática, assim, segundo nosso entendimento, está em resgatar aquilo que se objetiva essencialmente para o ensino de Matemática e foi reprimido pela tendência tradicional, como: adquirir conhecimentos relevantes para compreender a sociedade, solucionar problemas da vida cotidiana, além da "formação de capacidades intelectuais, na estruturação do pensamento e na agilização do raciocínio do aluno" (BRASIL, 1997, p. 15).

Para um ensino desta natureza, os participantes do processo - professores e alunos - necessitam manter um vínculo de cooperação e investigação. Primeiramente, porque o aluno não é um recipiente vazio, é um sujeito com interesses próprios, capaz de participar, discutir, dialogar e refletir e o professor não detém o conhecimento, é alguém que orienta o processo, faz as mediações entre aluno e conhecimento, entre aquilo que o aluno não sabe e tem curiosidade em aprender; é alguém que dialoga constantemente com as crianças (GASPERIN, 1990; SANTOS, 1990; TOZETTO, 1993; BRAUTIGAM, 2001).

Detectamos, ainda, algumas contribuições da Modelagem Matemática salientadas nos relatos:

- dinamiza o ensino de Matemática, o torna vivo; 
- instiga o gosto por aprender Matemática;

- permite maiores relações com o cotidiano das crianças;

- possibilita estudo de vários conteúdos;

- oferta maior liberdade ao aluno para raciocinar, pensar, demonstrar suas conclusões;

- instiga os alunos a fazerem perguntas e não se conformarem com que lhes é dito;

- considera os erros e as tentativas que os alunos fazem ao solucionar questões problemas, como pontes para construção do conhecimento;

- instiga a construção de saberes e conhecimentos que fundamentam possíveis transformações da realidade.

Tais questões convergem com aspectos justificativos apontados por Klüber e Burak (2007), como a contextualização das situações, forma dinâmica de construir os conhecimentos e interação entre os envolvidos no trabalho.

Num modelo de ensino que se sustenta em todas essas características construtivistas, destacando a valorização do aluno, o respeito a seus limites, tempo de aprendizagem e interesses, os conteúdos matemáticos são definidos atendendo as inquietações, as dúvidas existentes sobre um determinado tema. Dessa forma, Gasperin (1990), Santos (1990), Tozetto (1993) e Brautigam (2001) explicitam que os conteúdos matemáticos, em suas experiências com a Modelagem Matemática, não foram abordados de forma compartimentada, como é desvelado em muitos currículos e livros didáticos. Os conteúdos foram, na verdade, objetos de investigação e superação de curiosidades apresentadas pelas crianças.

\section{A abordagem dos conteúdos na Modelagem Matemática: experiências nos anos iniciais}

Os conteúdos de ensino, em geral, são identificados no âmbito escolar como os conhecimentos de uma determinada área a serem transmitidos aos alunos. Esse acesso aos conhecimentos, pelo ensino, é uma forma de democratização e garantia de uma cultura de base para as crianças. Estes, nas diferentes áreas de conhecimento e produção humana, assumem uma função social na prática educativa, referente ao "desenvolvimento individual e social dos indivíduos” (LIBÂNEO, 1994, p. 120). 
Em se tratando do ensino de Matemática, quando nos questionamos sobre os conteúdos específicos abordados por meio da Modelagem Matemática, estamos nos referindo aos conteúdos factuais, aqueles concernentes à parte da produção humana, que no caso da Matemática seriam os códigos, os símbolos, entre outros e que, por sua vez, não são indissociáveis da aprendizagem, compreensão e interpretação dos conceitos e princípios (ZABALA, 2010).

No que se refere ao definido pelas propostas curriculares para os anos iniciais, apresentamos o Quadro 2, construído a partir das leituras e interpretações dos Parâmetros Curriculares Nacionais (BRASIL, 1997):

Quadro 2 - Os conteúdos matemáticos para os anos iniciais do ensino fundamental apresentados nos Parâmetros Curriculares Nacionais

(continua)

\begin{tabular}{|c|c|}
\hline Blocos temáticos & Conceitos e Conteúdos \\
\hline $\begin{array}{l}\text { Números e } \\
\text { operações }\end{array}$ & $\begin{array}{l}1^{\circ} \text { ciclo (hoje } 1^{\circ} \text { ao } 3^{\circ} \text { Ano): Reconhecimento dos números. } \\
\text { Contagem, pareamento, estimativa e correspondência de } \\
\text { agrupamentos. Reconhecimento das operações, ênfase na adição e } \\
\text { subtração. } \\
2^{\circ} \text { ciclo (hoje } 4^{\circ} \text { e } 5^{\circ} \text { ano): Reconhecimento de números naturais e } \\
\text { racionais (com representações fracionárias e decimais), números } \\
\text { inteiros positivos e negativos. Operações envolvendo números } \\
\text { naturais e racionais. Cálculo simples de porcentagem. }\end{array}$ \\
\hline Espaço e forma & 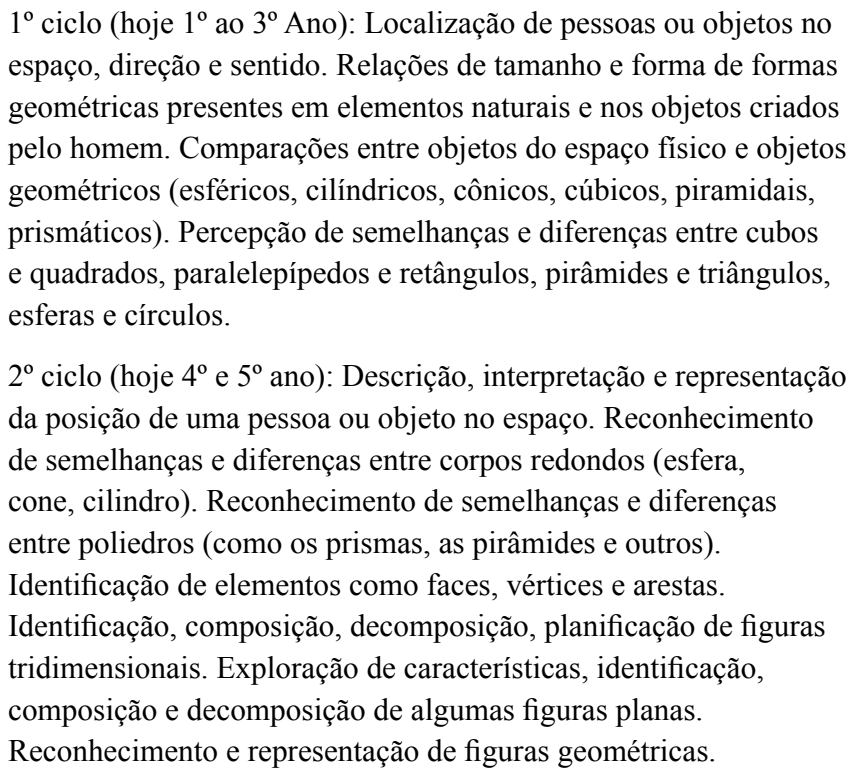 \\
\hline
\end{tabular}


Quadro 2 - Os conteúdos matemáticos para os anos iniciais do ensino fundamental apresentados nos Parâmetros Curriculares Nacionais

(conclusão)

\begin{tabular}{|c|c|}
\hline Blocos temáticos & Conceitos e Conteúdos \\
\hline $\begin{array}{l}\text { Grandezas e } \\
\text { medidas }\end{array}$ & $\begin{array}{l}1^{\circ} \text { ciclo (hoje } 1^{\circ} \text { ao } 3^{\circ} \text { ano): Comparação de grandezas de mesma } \\
\text { natureza. Unidades de tempo. Reconhecimento de cédulas e } \\
\text { moedas. Leitura de horas. } \\
2^{\circ} \text { ciclo (hoje } 4^{\circ} \text { e } 5^{\circ} \text { ano): Comparação de grandezas de } \\
\text { mesma natureza. Identificação de grandezas mensuráveis no } \\
\text { contexto diário (comprimento, massa, capacidade, superfície). } \\
\text { Reconhecimento e utilização de unidades usuais de medida (metro, } \\
\text { centímetro, quilômetro, grama, miligrama, quilograma, litro, } \\
\text { mililitro, metro quadrado, alqueire). Reconhecimento e utilização } \\
\text { de unidades usuais de tempo e de temperatura. Sistema monetário. } \\
\text { Cálculo de perímetro e de área. }\end{array}$ \\
\hline $\begin{array}{l}\text { Tratamento da } \\
\text { informação }\end{array}$ & $\begin{array}{l}1^{\circ} \text { ciclo (hoje } 1^{\circ} \text { ao } 3^{\circ} \text { ano): Leitura, interpretação, coleta e } \\
\text { organização de informações. Exploração da função do número } \\
\text { como código na organização de informações. Interpretação e } \\
\text { elaboração de listas, tabelas simples e gráficos. } \\
2^{\circ} \text { ciclo (hoje } 4^{\circ} \text { e } 5^{\circ} \text { ano): Leitura, interpretação, coleta, } \\
\text { organização e descrição de dados. Produção de textos escritos e } \\
\text { interpretação de dados apresentados por meio de tabelas e gráficos. } \\
\text { Ideias de probabilidade em situações-problema simples. }\end{array}$ \\
\hline
\end{tabular}

Fonte: Pesquisa Própria

Aos anos iniciais, de modo geral, são definidos conteúdos conceituais, noções de um determinado ramo da Matemática e que na escola devem ser selecionados criteriosamente para que se possa contribuir para o desenvolvimento de competências, habilidades, valores socialmente relevantes. Também valoriza-se o trabalho concomitante com os conteúdos atitudinais, referente aos comportamentos, atitudes e experiência no grupo escolar no meio (BRASIL, 1997).

No primeiro ciclo, do $1^{\circ}$ ao $3^{\circ}$ ano, oportuniza-se uma aproximação com os conteúdos matemáticos. Faz-se necessário resgatar as questões que as crianças observam no cotidiano, os jogos, as brincadeiras, os cálculos que elas desenvolvem informalmente. Valoriza-se, ainda, o uso de muitos materiais concretos, possíveis de visualização e exploração, pois, dessa forma, os conceitos matemáticos são interligados.

Por sua vez, no segundo ciclo, $4^{\circ}$ e $5^{\circ}$ ano, os alunos são instigados a solucionar problemas de forma mais abstrata, ampliam as hipóteses, as 
visões de contexto. Aprendem novos conteúdos que sustentarão a compreensão dos abordados nas etapas posteriores.

No que diz respeito ao trabalho com a Modelagem Matemática, esses conteúdos não são trabalhados isoladamente ou de forma linear, dão espaço, portanto, para abordagens que conectam e relacionam os conteúdos. Os Parâmetros Curriculares Nacionais (BRASIL, 1997) não citam a Modelagem como metodologia, mas os princípios são semelhantes porque se sustentam na interdisciplinaridade e relações entre os campos próprios da Matemática. Não se pode excluir, todavia, que os Parâmetros são utilizados nas escolas de anos iniciais na organização de seus currículos e planejamentos próprios e esses, por sua vez, muitas vezes engessam a atuação docente, pois os professores precisam dar conta de ensinar, o que nem sempre favorece a verdadeira aprendizagem pelas crianças.

Sobre a abordagem dos conteúdos a partir da Modelagem Matemática, não se pode desconsiderar que ela pode ser, segundo Burak (2004), desenvolvida em cinco (05) etapas: (I) escolha do tema, (II) pesquisa exploratória, (III) levantamento dos problemas, (IV) resolução dos problemas e (V) análise crítica das soluções.

Na primeira etapa - escolha do tema - os alunos são motivados a apresentar inquietações, temas de interesse. Numa turma, para Burak (1987), podem ser trabalhadas uma ou mais temáticas, depende de como o professor se organiza para atender as necessidades. Nos relatos, observamos que os professores trabalharam um único tema, justificado pela necessidade de melhor explorá-lo, e os conteúdos. Esses temas foram escolhidos pelas crianças. Gasperin (1990) e Brautigam (2001) partiram do tema "animais", o primeiro surgiu a partir do interesse da turma em conhecer o zoológico local e o segundo a partir de uma poesia contada pelo professor. Santos (1990) desenvolveu com os alunos as ações em Modelagem a partir de uma situação em que um determinado aluno relatou na aula e os outros demonstraram-se interessados, o caso da pintura da sala. Já Tozetto (1993) passou a desenvolver a Modelagem a partir de um momento vivido com as crianças, a visita a um colega que estava doente.

A pesquisa exploratória, o levantamento e a resolução de problemas não ocorrem numa sequência única. Em nosso entendimento, ocorreram diversas vezes, durante a realização da atividade, uma vez que esta não se reduziu a apenas uma aula, pois os problemas foram levantados em diferentes momentos que ocasionaram novas pesquisas e a utilização de conteúdos matemáticos. Um exemplo disso pode ser a pesquisa de Gasperin (1990), pois ao visitarem o zoológico e conhecer os animais que viviam no espaço os 
alunos demonstraram curiosidade sobre a alimentação e logo foram buscar informações em livros e com pessoas que trabalhavam no local. Identificado isso, pesquisaram a quantidade de alimentos, o custo e, neste momento, na resolução de problemas, se apresentou os conteúdos matemáticos de forma mais destacada.

Na quinta etapa - referente à análise das soluções - percebemos que os professores puderam identificar os progressos dos alunos, suas aprendizagens. Nesta etapa, de finalização do processo, detectamos algumas características autoavaliativas, como participação e envolvimento dos alunos.

Considerando essas, pudemos interpretar que, nas experiências vividas por Gasperin (1990), Santos (1990), Tozetto (1993) e Brautigam (2001), os conteúdos específicos de matemática tonaram-se visíveis a partir da pesquisa exploratória, segunda etapa, após a apresentação, por parte dos alunos, de suas inquietações sobre o tema escolhido.

O Quadro 3 traz a representação dos conteúdos abordados partir das temáticas escolhidas pelas turmas, professores e alunos.

Quadro 3 - Temas escolhidos e conteúdos abordados

\begin{tabular}{|c|c|c|}
\hline Trabalhos & $\begin{array}{l}\text { Temas } \\
\text { escolhidos }\end{array}$ & Conteúdos matemáticos abordados \\
\hline $\begin{array}{l}\text { Gasperin } \\
(1990)\end{array}$ & $\begin{array}{l}\text { Zoológico } \\
\text { (animais } \\
\text { existentes no } \\
\text { zoológico } \\
\text { municipal) }\end{array}$ & $\begin{array}{l}\text { - Números cardinais e decimais. } \\
\text { - Sistema de medidas: unidades de medidas de massa a } \\
\text { partir da alimentação destinada aos animais. } \\
\text { - Sistema monetário a partir dos gastos com } \\
\text { alimentação e outras despesas dos animais. } \\
\text { - Operações matemáticas: adição e subtração. }\end{array}$ \\
\hline $\begin{array}{l}\text { Santos } \\
(1990)\end{array}$ & $\begin{array}{l}\text { Pintura da sala } \\
\text { de aula a partir } \\
\text { de uma situação } \\
\text { visualizada pelos } \\
\text { alunos numa } \\
\text { novela. } \\
\end{array}$ & $\begin{array}{l}\text { - Figuras geométricas. } \\
\text { - Unidades de medidas de comprimento a partir da sala. } \\
\text { - Unidades de medida de superfície a partir dos objetos } \\
\text { presentes na sala. } \\
\text { - Sistema monetário a partir dos gastos com materiais. } \\
\text { - Porcentagem. }\end{array}$ \\
\hline $\begin{array}{l}\text { Tozetto } \\
\text { (1993) }\end{array}$ & $\begin{array}{l}\text { Visita ao colega } \\
\text { adoentado. }\end{array}$ & $\begin{array}{l}\text { - } \text { Classificação. Seriação. } \\
\text { - Geometria. } \\
\text { - Sistema de numeração. } \\
\end{array}$ \\
\hline $\begin{array}{l}\text { Brautigam } \\
(2001)\end{array}$ & $\begin{array}{l}\text { Gato a partir da } \\
\text { poesia "Pé de } \\
\text { gato". }\end{array}$ & $\begin{array}{l}\text { - Unidades de medida de massa a partir da alimentação } \\
\text { dos animais. } \\
\text { - Sistema monetário a partir da alimentação e despesas } \\
\text { dos gatos. } \\
\text { - Porcentagem a partir das raças dos gatos. Tratamento } \\
\text { de informações: gráficos. }\end{array}$ \\
\hline
\end{tabular}

Fonte: Pesquisa Própria. 
Para Tozetto (1993, p. 21), "a construção do conhecimento não se dá por compartimento" e muito menos sem relação com o cotidiano das crianças, assim, a escolha da temática, como esboçado no Quadro 2, com a participação das crianças, se apresenta, no mínimo, relevante e coerente, pois abre um leque para abordagem de diferentes conteúdos.

Como conteúdos predominantes ao trabalho com turmas da $3^{\mathrm{a}}$ e $4^{\mathrm{a}}$ série, Gasperin (1990), Tozetto (1993) e Brautigam (2001) trabalharam com números, operações, sistema monetário, sistema de medidas. Estes conteúdos apareceram nos diferentes temas, sem estarem definidos a priori, o que indica que é possível visualizar e aprender Matemática a partir de diferentes contextos e de diferentes formas.

No que concerne a números e operações, os "alunos têm a oportunidade de ampliar ideias" (BRASIL, 1997, p. 83), uma vez que no primeiro ciclo se enfatiza muito esse bloco temático. São conteúdos básicos e presentes em todas as outras propostas da matemática, em tentativas de solucionar diferentes problemas. A situação problema, todavia, com maior evidência, foi uso do sistema monetário, que se tem uso quase que diariamente na vida dos sujeitos.

O trabalho com sistemas de medidas oferta às crianças a possibilidade de compreender melhor as formas de medição e que assimilem conceitos favoráveis para que escolham determinadas unidades a fim de solucionar problemas, em sala de aula ou no cotidiano.

Tozetto (1993), por sua vez, por tratar do primeiro ciclo, etapa de alfabetização, se preocupou em abordar, diante das questões postas em diálogo com as crianças de uma primeira série, os conhecimentos lógico-matemáticos. A utilização de objetos manipuláveis, de atividades de contagem, juntar e ordenar e o próprio uso da geometria, se caracterizam como subsídios para a criança melhor compreender, descrever, representar, organizar informações e o próprio meio em que vive (BRASIL, 1997). Nessa linha, Nogueira (2011) expressa que são aspectos/situações favoráveis e necessários para a construção do número e compreensão dos conteúdos previstos para a área.

Em síntese, considerando os quadros 1 e 2 , todos os conteúdos trabalhados fazem parte do proposto, oficialmente, para os anos iniciais. Mas o grande diferencial do trabalho com estes conteúdos esteve no uso da Modelagem, pois eles foram abordados à medida que se faziam relevantes e, principalmente, davam conta de responder os problemas levantados pelas crianças. Além disso, não estiveram distantes do contexto e foram aprendidos a partir da interação e do diálogo. Também, destacamos que os campos da 
Matemática se apresentaram interligados, rompendo com o ensino usual, fragmentado.

A possibilidade dada às crianças de fazer descobertas, estabelecer relações com outras áreas do conhecimento, desenvolver e organizar seus pensamentos, representa situação indispensável para que ela se aproprie dos conceitos matemáticos, reconheça e faça uso de suas linguagens e simbologias (ARAGÃO, 2010; ZIMER, 2010).

Há que ser mencionado, ainda, que o trabalho com os conteúdos matemáticos, por meio da Modelagem, rompeu com que Tomaz e David (2008) consideram limitação da escola: ausência de contextualização e interdisciplinaridade. A contextualização pela possibilidade de partir de um tema e ser de interesse das crianças e a interdisciplinaridade, como fator destacável, pela presença de conceitos e conteúdos de outras disciplinas.

\subsection{A interdisciplinaridade na Modelagem Matemática}

A interdisciplinaridade, integração das áreas de conhecimento, é um aspecto justificativo para o uso da Modelagem Matemática no ensino de Matemática (KLÜBER; BURAK, 2007). Logo, pode-se mencionar que os conteúdos matemáticos abordados a partir da Modelagem não aparecem desconexos das demais áreas. De forma breve, poderíamos mencionar que nos relatos é possível detectar que se promoveu ruptura com o modelo disciplinar de tratar os conhecimentos escolares.

Gasperin (1990), ao trabalhar com o tema relacionado a animais (do zoológico da cidade), resgatou questões concernentes aos seres vivos (alimentação, locomoção, ambiente). Por sua vez, Santos (1990), com a situação temática referente à pintura da sala, trabalhou paisagem local, natureza, ambiente e gêneros textuais (recibo, cheque).

Tozetto (1993), a partir da visita a um colega doente, que se constitui em temática, também abordou paisagem local, ambiente (plantas, animais), aspectos visualizados durante o percurso da visita e, também, corpo humano e saúde.

Brautigam (2001), que trabalhou com o tema gato e enfatizou a interdisciplinaridade em seu relato, abordou, além dos conteúdos matemáticos: seres vivos e ambiente, questões relacionadas à saúde, alimentação e higiene (na discussão sobre a vida do gato e do ser humano).

Além destas possíveis relações, foi possível identificar nos trabalhos, questões concernentes à escrita, oralidade, leitura e interpretação, como oportunidade de aprendizagem da língua materna, presente em todos os 
contextos. Também vivenciaram questões morais e éticas: respeito mútuo, solidariedade, entre outros oportunizados pela constante interação.

Esses exemplos demonstram que os conteúdos não foram "unidos" forçosamente, mas que pela postura dialógica e investigativa, pode-se explicar e discutir diferentes curiosidades que os conhecimentos matemáticos, respeitando a definição das áreas, não explicariam e que, por outro lado, somente com eles é possível ter uma visão específica de mundo. Dito de outra forma, houve uma interação constante das áreas, registrando explicações mais complexas e abrangentes (BORGO; BURAK, 2011).

Há também que ser enfatizado que uma metodologia investigativa e interdisciplinar, características da Modelagem, instiga a todo o momento leitura, análise, interpretação. Assim, constitui-se num meio de solucionar a problemática de que o ensino de Matemática esbarra na interpretação ${ }^{1}$, que os alunos não são leitores e, por isso, não conseguem pensar matematicamente problemas da vida e muito menos problemas escolares.

\section{Considerações finais}

A Modelagem Matemática nos anos iniciais, na condição de temática de pesquisa ou no que se refere a experiências vividas, ainda é incipiente. Há poucos registros e divulgação sobre o trabalho com essa metodologia com crianças (SILVA; KLÜBER, 2011). E as poucas e tímidas pesquisas, surgidas desde os anos 1990, expressam em geral um incomodo e desconforto com o modelo em que o ensino de Matemática ocorre: mecanicista, com pouco ou nenhum diálogo.

É por este descontentamento, em nossa compreensão, que a Modelagem Matemática representa uma ruptura com modelos preestabelecidos e uma possibilidade de melhorias no ensino de Matemática, pois é, em essência, uma proposta dialógica, investigativa e interdisciplinar.

No que se refere aos conteúdos matemáticos, pode-se mencionar que, embora muitos professores se preocupem apenas em cumprir o currículo e, muitas vezes, se limitam ao material de apoio, como o livro didático, não há uma forma única de ensinar ou de abordar os conteúdos em sala.

Na Modelagem Matemática os conteúdos não se dão de forma estanque, não se limitam a si mesmo e a todo o momento são relacionados com outras produções humanas e com o vivido pelas crianças.

\footnotetext{
${ }^{1}$ Conforme reportagem da Gazeta do Povo, disponível em http://www.gazetadopovo.com.br/educacao. Acesso em 10 de março. 2014
} 
Não se pode negar, todavia, que a abordagem dos conteúdos matemáticos depende muito da criatividade, flexibilidade e disposição do professor em atender ou "tentar" responder às questões surgidas durante o processo. Para que a Modelagem aconteça, é necessário que o professor esteja disposto ao novo e que também tenha domínio sobre os conteúdos específicos da Matemática e o pensar próprio desta área de conhecimento.

A Modelagem Matemática, em suma, como descrito nos relatos em discussão, descortina novas possibilidades de empreender o ensino de Matemática: aulas menos cansativas, conteúdos não fragmentados, intensa relação escola e vida.

\section{Referências}

ARAGÃO, R. M. R. de. Rumo à educação do século XXI: para superar os descompassos do ensino nos anos iniciais de escolaridade. In: BURAK, D.; PACHECO, E. R.; KLÜBER, T. E. (Org.). Educação Matemática: reflexões e ações. Curitiba: CRV, 2010, p. 11-25.

BRASIL. Secretaria de Educação Fundamental. Parâmetros Curriculares Nacionais: Matemática. Brasília: MEC, 1997.

BRAUTIGAM, V. L. L. Modelagem matemática: construindo a interdisciplinaridade. 2001. 75p. Monografia (Especialização Psicopedagogia) - Universidade Estadual do Centro-Oeste do Paraná, Guarapuava, 2001.

BURAK, D. Modelagem matemática: uma alternativa para o ensino de matemática na $5^{a}$ série. 188 p. Dissertação (Mestrado em Educação Matemática) - Universidade Estadual Paulista, Rio Claro, 1987.

. Modelagem matemática: ações e interações no processo de ensino-aprendizagem. 1992. 460 p. Tese (Doutorado em Educação) Faculdade de Educação da Universidade Estadual de Campinas, Campinas, 1992.

. Modelagem matemática e a sala de aula. In Encontro Paranaense de Modelagem em Educação Matemática, 01, 2004, Londrina. Anais... Londrina: UEL, 2004.

As Diretrizes Curriculares Nacionais para o ensino de Matemática e a modelagem matemática. Revista Perspectiva, Erechim, v. 29, n. 113, p. 153-161, 2005. 
BORGO, V. T. K.; BURAK, D. Modelagem matemática e interdisciplinaridade: perspectivas para o ensino de Matemática nos anos iniciais. In Seminário de Pesquisa do PPE, 2011, Maringá. Anais... Maringá: UEM, 2011, p. 01-19.

CARRAHER, T.; CARRAHER, D.; SCHLIEMANN, A. L. Na vida dez, na escola zero. 3 ed. São Paulo: Cortez, 1988.

FREIRE, P. Pedagogia do oprimido. 48 ed. Rio de Janeiro: Paz e Terra, 2005.

GASPERIN, I. M. Modelagem matemática: uma metodologia para o ensino de Matemática na $3^{\mathrm{a}}$ série do $1^{\circ}$ grau. 1990. 36p. Monografia (Especialização em ensino de Matemática e Ciências) - Faculdade Estadual de Filosofia, Ciências e Letras de Guarapuava, Guarapuava, 1990.

KLUBER, T. E.; BURAK, D. Modelagem matemática: pontos que justificam a sua utilização no ensino. In: Encontro Nacional de Educação Matemática, 2007, Belo Horizonte, MG. Anais... Belo Horizonte: UNI-BH, 2007, p 1-19. LIBÂNEO, J. C. Didática. São Paulo: Cortez, 1994.

LINS, R. C. Por que discutir teoria do conhecimento é relevante para a Educação Matemática. In: BICUDO, M. Ap. V. (Org.). Pesquisa em Educação Matemática: concepções e perspectivas. São Paulo: UNESP, 1999.

LOPES, A. R. L. V.; MARAFIGA, A. W.; SILVA, D. S. G. da; BOROWSKY, H. G.; HUNDERTMARCK, J.; FRAGA, L. P.; POSEBON, S. Pensando na Educação Matemática dos anos iniciais: alguns apontamentos. In: Conferência Interamericana de Educação Matemática, 2011, Recife, Brasil. Anais... Recife: UFPE, 2011, p. 1-6.

NOGUEIRA, C. M. I. Pesquisas atuais sobre a construção do conceito de número: para além de Piaget? Educar em Revista, Curitiba, n. Especial, p. 109-124, 2011.

SANTOS, M. E. P. dos. Modelagem matemática: uma metodologia para o ensino de Matemática na $4^{\mathrm{a}}$ série do $1^{\circ}$ grau. 1990. 62p. Monografia (Especialização em ensino de Matemática e Ciências) - Faculdade Estadual de Filosofia, Ciências e Letras de Guarapuava, Guarapuava, 1990.

SILVA, V. da S.; KLÜBER, T. E. Um olhar pedagógico sobre a modelagem matemática nas séries iniciais do Ensino Fundamental. In: Seminário de 
Pedagogia, 2, 2011, Irati. Anais... Irati: Departamento de Pedagogia da Universidade Estadual do Centro-Oeste, 2011, p. 14.

. Modelagem matemática nos anos iniciais do Ensino Fundamental: reflexões e apologia aos seus usos. In: ALENCAR, E. S. de; LAUTENSCHLAGER, E. Modelagem matemática nos anos iniciais. São Paulo: Sucesso, 2014, p. 07-24.

TOMAZ, V. S.; DAVID, M. M. M. S. Interdisciplinaridade e aprendizagem da Matemática em sala de aula. Belo Horizonte: Autêntica, 2008.

TOZETTO, M. I. Alfabetização Matemática: uma experiência com modelagem matemática. 1993. 54p. Monografia (Especialização em ensino de Matemática e Ciências) - Faculdade Estadual de Filosofia, Ciências e Letras de Guarapuava, Guarapuava, 1993.

ZABALA, A. A prática educativa: como ensinar. Porto Alegre: Artmed, 2010.

ZIMER, T. T. B. Matemática. In: PARANÁ. Secretaria de Estado da Educação. Ensino Fundamental de nove anos: orientações pedagógicas para os anos iniciais. Curitiba: SEED, 2010, p. 153- 166. 